\title{
To Assess The Effectiveness of Breathing Exercise on Labour Pain and Behavioral Response of Primi Gravid Mothers During First Stage of Labour at Selected Maternity Hospitals
}

\author{
Shalini Moon, Manjusha Mahakarkar and Pradnya Sakle \\ Smt. Radhikabai Meghe Memorial College of Nursing, Datta Meghe Institute of \\ Medical Sciences (Deemed to be University) Sawangi (Meghe) Wardha, India
}

\begin{abstract}
Childbirth is hard and headaches occur, however women's our bodies are designed to offer birth. The form of the pelvis, hormones, effective muscle mass and extra all paintings collectively that will help you convey your child into the world - before, in the course of and after childbirth. AIM: To assess the effectiveness of breathing exercise on labour pain and behavioral response of primi gravid mothers during first stage of labour, at selected Maternity hospitals. Material and methods: The design was adopted true experimental design with pre-test post-test control group design was used for this study. The sample consisted of 40 mothers, 20 in experimental group and 20 in control group. The simple random sampling technique was used to select the samples. The data was collected by using Baseline Performa and Observational check list. Result: The effect of breathing exercises on pain and behavioral response during the first stage of labour among primigravida mothers in the experimental group. The assessment is done before and after breathing exercises. The mean, standard deviation and range are compared, and student's paired't' test was applied at 5\% level of significance. The mean score for pain before breathing exercises and after breathing is 8.85 and is 3.30. The standard deviation for pain before and after breathing exercises is 0.67 and 0.47 . The range before and after breathing exercises is between $8-10$ and 3 - 4. Mean score for behavioral response before and after breathing exercises is 8.70 and 3.25. Standard deviation before and after breathing exercises is 0.65 and 0.44 . The range before and after breathing exercises is between $8-10$ and between $3-4$. Mean difference for pain is between $5.55 \pm 0.60$ and for behavioral responses it is between $5.45 \pm$ 0.68. Conclusion: The study results concluded that respiration workout is a powerful non pharmacological intervention for decreasing labor pain.
\end{abstract}

KEY WORDS: ASSESS, BREATHING EXERCISE, BEHAVIORAL RESPONSE, EFFECTIVENESS, LABOUR PAIN, PRIMIGRAVIDA MOTHERS,

\section{INTRODUCTION}

Child birth is one of the most marvelous and memorable segment in women's life. It does not really matter if the child is the first, second or the third.Each experience is unique and calls for a celebration. Labour is a natural process by which a viable fetus, at the end of 28 weeks

Biosc Biotech Res Comm P-ISSN: 0974-6455 E-ISSN: 2321-4007
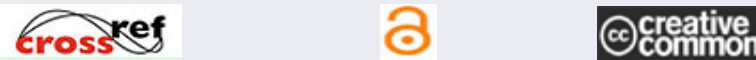

Identifiers and Pagination

Article Information

Year: 2021 Vol: 14 No (9) Special Issue

Received: $10^{\text {th }}$ May 2021

Pages: 140-149 Accepted after revision: $15^{\text {th }}$ June 2021

This is an open access article under Creative

Commons License Attribn 4.0 Intl (CC-BY).

DOI: $h t t p: / / d x$.doi.org/10.21786/bbrc/14.9.28 or more is expelled from the uterus. The fear and anxiety about child birth often prevents most women from enjoying this experience.Although labour is often thought of as one of the most painful events in human life. No two women have the same degree of labour pain and no two labour are exactly alike. Labour pain ranges widely from woman to woman and even from pregnancy. Studies have shown that around 70\% of women experience awful labour and around 10\% of them experience an almost painless.

Background and Need of the Study: Pain is highly unpleasant and very personal sensation that cannot be shared with others. Although pain is a universal experience, its exact nature remains a mystery. Pain during labour is caused by the contraction of the muscles 
of the uterus and by the pressure on the cervix. This is mainly manifested as cramping in the abdomen, groin and back, as well as a tired, achy feeling all over the body. Some women experience pain in their sides or thighs as well. Other causes of pain during labour include pressure on the bladder and bowels by the head and stretching of the birth canal and vagina.

Pain is always present in primi mothers. To ease the pain and to improve the behavioral response of the mother's pharmacological and non-pharmacological management are important. Pharmacological approaches are directed at eliminating the physical sensation of labour pain, whereas non pharmacological approaches such as relaxation, breathing techniques, positioning, massage, hydrotherapy, hot and cold therapy, music guided imagery, acupressure and aromatherapy are simple and safe which enhance the comfort of women and help them to achieve an effective coping level for their labour experience without any maternal and foetal complications. Pregnancy is a time of great change for a woman, not only for the obvious physical change in her body, even her emotional state changes several times throughout the day. Each woman comes into labour with a set of expectations: fear, preparation, pain threshold, personality and behavioral makeup, and ways of experiencing what is happening to her, which has to be maintained effectively. The time of labour and birth, though short in comparison with the length of pregnancy, is the most dramatic and significant period of pregnancy.

Labour pain is the most severe pain experienced by the women. Parity also influences labour pain, that is, primigravida women experience more pain during labour than multigravida mothers. 2 Recent studies have shown that the incidence of caesarean sections is increasing throughout the developed and developing countries. Majority of women (68\%) are requesting for caesarean section because of psychological indications. Women with adequate psychological support and relaxation techniques had reduced the incidence of caesarean section and 38\% of them agreed for normal vaginal delivery. Relaxation techniques, mainly breathing exercises, had brought $50 \%$ reduction in caesarean section for psychological indications. Breathing technique is one of the widest, safest, and commonest method of pain relief measures. The theory behind childbirth breathing patterns is based on the concentration required to focus on breathing. During a contraction, thought process is redirected from a pain response to breathing technique. 1 Among various breathing exercises, slow paced breathing exercise is one of the simplest. It is slow, deep breathing that increases relaxation. This naturally brings about slower breathing, similar to that during sleep. It can be used as long as possible during labour because it promotes relaxation and oxygenation.

This breathing technique is a deeper, slower way of breathing, which involves filling the lungs to its full capacity when inhaling and then pushing out as much air as possible when exhaling. These breathing techniques are used only during contraction. In between contraction women has to relax to conserve energy where breathing should be smooth and deep through the nose and then letting air through the mouth. This type of breathing is also called as cleansing breath.

A quasi-experimental study was conducted to determine the effectiveness of breathing exercises on duration, outcome of labour, and behavioural response of gravid women during the first stage of labour in a selected hospital at Mangalore. The sample comprised of 20 subjects each in experimental and control group, selected by purposive sampling technique. Data was collected using a structured observation checklist. The results showed the mean percentage scores for the behavioural responses of women in the experimental group to be higher (94.04\%) than that of the control group (62.55\%). There was significant difference in behavioural responses of women in labour in both experimental and control group ( $\mathrm{t} 38=23.19, \mathrm{p}<0.05)$, and also a significant difference in the duration of the first stage of labour in prim gravid mothers $(\mathrm{t} 18=2.40, \mathrm{p}<0.05)$. The results revealed that breathing exercises during labour are effective in reducing the duration and outcome of labour. Breathing exercises does not require equipment and machinery, it require efficient child birth educator and the willingness to practice the exercises on the part of pregnant women.8Since the breathing exercise are easy to practice and help in promoting positive outcome, the researcher felt the need to educate primigravida mothers to practice slow paced breathing during first stage of labour to reduce labour pain.

\section{Objectives}

1. To assess pain intensity level among the Primi gravid mothers during first stage of labour in experimental and control group.

2. To assess the behavioral response of primi gravid mothers during first stage of labour in experimental and control group.

3. To determine the effectiveness of breathing exercise on labour pain among primigravid mothers during first stage of labour.

4. To determine the effectiveness of breathing exercise on behavioral response among primigravid mothers during first stage of labour

5. To determine the association between selected demographic variables and pain of primigravid mothers during first stage of labour.

6. To determine the association between selected demographic variables and behavioral response of primigravid mothers during first stage of labour.

\section{Assumptions}

1. Primi mothers in first stage of labour will have severe pain during uterine contractions.

2. Breathing exercise may have an effect on pain and behavioral response of primigravida mothers.

3. Behavior responses of primi mothers in labour can be identified by observational checklist. 


\section{Hypothesis}

H1- There is a significant difference between the pain score of primigravid mothers in experimental group and control group.

$\mathrm{H} 2$ - There is a significant difference between the behavioral response of primigravid mothers in experimental group and control group.

H3- There is a significant association between the selected demographic variables and pain scores of primigravid mothers in experimental group.

H4- There is a significant association between the selected demographic variables and behavioral response of primigravid mothers in experimental group.

\section{Variables}

Independent variable: Breathing exercises during first stage of labour.

Dependent variable: Labour Pain and Behavioral Response during first stage of labour.

Demographic variables: Age, education, Religion, area of residence, occupation, income and family type.

\section{Methodology}

- Research approach: - An interventional research approach.

- Research design:- The design was adopted true experimental design with pre-test post-test control group.

- $\quad$ Setting of the study: - The study will be conducted in selected Maternity hospitals at Wardha.

- Sampling technique:-Probability Simple random sampling technique.

- Sample: - Primigravida mothers at first stage of labour.

- Sample size :- 40 ( 20 in experimental group and 20 in the control group)

- Criteria for sample selection :-

\section{Inclusion Criteria:-}

\section{Primi gravid mothers who are:}

1. Mother in first stage of normal labour.

2. Mother in labour with cervical dilatation more than $4 \mathrm{~cm}$

3. Admitted in the Labour ward for normal delivery.

4. Willing to participate

5. Able to communicate in Hindi, Marathi and English,

Table 1. Percentage wise distributions of primigravid mother according to their demographic variables. $\mathrm{N}=20$ (in each group)

\begin{tabular}{|c|c|c|c|c|c|}
\hline \multirow{2}{*}{$\begin{array}{l}\text { Demographic } \\
\text { variables }\end{array}$} & & \multicolumn{2}{|c|}{ Experimental Group } & \multicolumn{2}{|c|}{ Control Group } \\
\hline & & Frequency & $\begin{array}{c}\text { Percentage } \\
(\%)\end{array}$ & Frequency & $\begin{array}{c}\text { Percentage } \\
(\%)\end{array}$ \\
\hline \multirow[t]{4}{*}{ Age in years } & $19-23$ & 13 & $65 \%$ & 15 & $75 \%$ \\
\hline & $24-28$ & 6 & $30 \%$ & 5 & $25 \%$ \\
\hline & $29-33$ & 1 & $5 \%$ & 0 & $0 \%$ \\
\hline & 34 Et Above & 0 & $0 \%$ & 0 & $0 \%$ \\
\hline \multirow[t]{4}{*}{ Educational Status } & Illiterate & 0 & $0 \%$ & 0 & $0 \%$ \\
\hline & Primary & 2 & $10 \%$ & 6 & $30 \%$ \\
\hline & Secondary & 12 & $60 \%$ & 13 & $65 \%$ \\
\hline & Graduation \&t above & 6 & $30 \%$ & 1 & $5 \%$ \\
\hline \multirow[t]{4}{*}{ Religion } & Hindu & 12 & $60 \%$ & 15 & $75 \%$ \\
\hline & Muslim & 0 & $0 \%$ & 0 & $0 \%$ \\
\hline & Christian & 1 & $5 \%$ & 0 & $0 \%$ \\
\hline & Others & 7 & $35 \%$ & 5 & $25 \%$ \\
\hline \multirow[t]{3}{*}{ Occupation } & Housewife & 15 & $75 \%$ & 16 & $80 \%$ \\
\hline & Daily Wages & 1 & $5 \%$ & 3 & $15 \%$ \\
\hline & Employees & 4 & $20 \%$ & 1 & $5 \%$ \\
\hline
\end{tabular}

\section{Exclusion Criteria:-}

\section{Primigravida mothers who are:}

1. Mother with high risk pregnancy like hypertension, diabetes, multiple pregnancy etc.
2. Prolonged and precipitated labour.

Discription of Tools

The tools consist of 3 sections: 
Section 1: Baseline Performa.(age, education, religion, occupation)

Section 2: FLAAC pain assessment scale tool (0-10) to assess the pain. (Updated September 03-2009 which is standardized tool)

Section3: VAS (Visual Analogue Scale) behavioral response (pain assessment) scale which is standardized tool

\section{RESULTS}

\section{The analysis and interpretation of the finding are given} under the following sections.

Section A: Percentage wise distribution of Primi gravid mothers according to their

Demographic variables.

Section B: Assess pain intensity level among the primi gravid mothers during first stage of labour in experimental and control group.

Table 2. Pain during the first stage of labour among primigravida mothers in experimental group before breathing exercise. $\mathrm{N}=20$

\begin{tabular}{|l|c|c|c|}
\hline & Mean & Standard Deviation & Range \\
\hline Pain & 8.85 & 0.67 & $8-10$ \\
\hline
\end{tabular}

Table 3. Pain and behavioral responses during first stage of labour among primigravida mothers in control group. $\mathrm{N}=20$

\begin{tabular}{|l|c|c|c|}
\hline & Mean & Standard Deviation & Range \\
\hline Pain & 8.95 & 0.68 & $8-10$ \\
\hline
\end{tabular}

Table 3. Pain and behavioral responses during first stage of labour among primigravida mothers in control group. $\mathrm{N}=20$

\begin{tabular}{|c|c|c|c|}
\hline & Mean & Standard Deviation & Range \\
\hline $\begin{array}{c}\text { Behavioral } \\
\text { Responses }\end{array}$ & 8.70 & 0.65 & $8-10$ \\
\hline
\end{tabular}

Section C: Assess the behavioral response of primi gravid mothers during first stage of labour in experimental and control group.

Section D:Assess the effectiveness of breathing exercises on labour pain among primigravid mothers during first stage of labour.
Table 5. Behavioral responses during the first stage of labour among pimigarvida mothers in control group before breathing exercises. $\mathrm{N}=20$

\begin{tabular}{|c|c|c|c|}
\hline & Mean & Standard Deviation & Range \\
\hline $\begin{array}{c}\text { Behavioral } \\
\text { Responses }\end{array}$ & 8.85 & 0.58 & $8-10$ \\
\hline
\end{tabular}

Section E (A) : Associate the effect of breathing exercises on pain during the labour pain among primigravid mothers in the experimental group with the selected demographic variables.

Section E-(B): Associate the effect of breathing exercises on behavioral responses during labour pain among primigravid mothers in the experimental group with selected demographic variables.

Table No. 1 shows that the distribution of subjects according to their age. $65 \%$ of subjects in the experimental group and 75\% in the control group are belongs to the age group of 19 - 23years, 30\% in the experimental group and 25\% in the control group belongs to the age group of $24-28$ years, $5 \%$ in the experimental group were belong to the age group of 29 - 33years and $0 \%$ from the both group of 34 years and above.

The distribution of the subjects according to their education. 10\% from the experimental group and 30\% from the control group were educated up to primary level, 60\% from the experimental group and 65\% from the control group were up to secondary education, 30\% from the experimental group and 5\% from the control group were educated up to graduation and above and no subjects were illiterate.

The distribution of subjects according to their religion $.60 \%$ from the experimental group and 75\% from the control group were belongs to the Hindu religion, 5\% in the study group belong to Christian religion and 35\% in the experimental group and 25\% from the control group were belongs to the other religion and no subjects were from the Muslim religion in both experimental and control group.

The distribution of the subjects according to their occupation. $75 \%$ from the experimental group and $80 \%$ from the control group were house wives, 5\% from the experimental group and 15\% from the control were daily wages and 20\% from the experimental group and 5\% from the control group are employees.

Section B: Assess pain intensity level among the Primi gravida mothers during first stage of labour in experimental and control group.

Table No.2 shows the mean, standard deviation and range of pain of primigravida mothers in the experimental group before breathing exercises. The mean score for 
pain is 8.85 and standard deviation is 0.67 . The range for pain was between 8 and 10 .

Table No. 3 reveals the mean, standard deviation and range of pain of primigravida mothers in the control group. The mean score for pain is 8.95 and standard deviation is 0.68. Mean score and the range for pain were between 8 and 10 .

Section C: Assess the behavioral response of primi gravida mothers during first stage of labour in experimental and control group.

Table 6. Assessment of the effect of breathing exercises on labour pain during the first stage of labour among primigravida mothers in the experimental group $\mathrm{N}=20$ (each group)

\begin{tabular}{|c|c|c|c|c|c|c|c|}
\hline & & Mean & $\begin{array}{c}\text { Standard } \\
\text { Deviation }\end{array}$ & Range & $\begin{array}{c}\text { Mean } \\
\text { Difference }\end{array}$ & t-value & p-value \\
\hline \multirow{2}{*}{ Pain } & Before t/t & 8.85 & 0.67 & $8-10$ & $5.55 \pm 0.60$ & 41.03 & $\begin{array}{c}0.000 \\
\text { S, } p<0.05\end{array}$ \\
\cline { 2 - 8 } & After t/t & 3.30 & 0.47 & $3-4$ & & & \\
\hline
\end{tabular}

Table 7. Assessment of the effect of breathing exercises on labour pain and behavioral responses during the first stage of labour among parturient mother in the experimental group $\mathrm{N}=20$

\begin{tabular}{|c|c|c|c|c|c|c|c|}
\hline & & Mean & $\begin{array}{l}\text { Standard } \\
\text { Deviation }\end{array}$ & Range & $\begin{array}{c}\text { Mean } \\
\text { Difference }\end{array}$ & t-value & p-value \\
\hline \multirow{2}{*}{$\begin{array}{l}\text { Behavioral } \\
\text { Responses }\end{array}$} & Before $t / t$ & 8.70 & 0.65 & $8-10$ & $5.45 \pm 0.68$ & 35.51 & \multirow{2}{*}{$\begin{array}{c}0.000 \\
S, p<0.05\end{array}$} \\
\hline & After $\mathrm{t} / \mathrm{t}$ & 3.25 & 0.44 & $3-4$ & & & \\
\hline
\end{tabular}

\begin{tabular}{|c|c|c|c|c|c|}
\hline \multicolumn{2}{|l|}{$\begin{array}{l}\text { Demographic } \\
\text { variables }\end{array}$} & $\begin{array}{c}\text { No. of Primigravida } \\
\text { Mothers }\end{array}$ & Mean score & $\begin{array}{c}\mathrm{F}- \\
\text { value }\end{array}$ & $\begin{array}{c}\mathrm{p}- \\
\text { value }\end{array}$ \\
\hline \multirow[t]{2}{*}{ Age (yrs) } & $19-23$ & $13(65 \%)$ & $3.23 \pm 0.43$ & 0.87 & $\begin{array}{c}0.43 \\
\text { NS, } p>0.05\end{array}$ \\
\hline & $\begin{array}{c}24-28 \\
29-33 \\
34 \text { \& } \text { Above }\end{array}$ & $\begin{array}{l}6(30 \%) \\
1 \quad(5 \%) \\
0(0 \%)\end{array}$ & $\begin{array}{l}3.50 \pm 0.54 \\
3.00 \pm 0.00 \\
0.00 \pm 0.00\end{array}$ & & \multirow[b]{2}{*}{$\begin{array}{c}0.66 \\
\text { NS, } p>0.05\end{array}$} \\
\hline \multirow[t]{2}{*}{ Educational Status } & Illiterate & $0(0 \%)$ & $0.00 \pm 0.00$ & 0.42 & \\
\hline & $\begin{array}{c}\text { Primary } \\
\text { Secondary } \\
\text { Graduation \&t } \\
\text { Above }\end{array}$ & $\begin{array}{c}2(10 \%) \\
12(60 \%) \\
6(30 \%)\end{array}$ & $\begin{array}{l}3.50 \pm 0.70 \\
3.33 \pm 0.49 \\
3.16 \pm 0.40\end{array}$ & & \multirow[b]{2}{*}{$\begin{array}{c}0.40 \\
\text { NS, } p>0.05\end{array}$} \\
\hline Religion & Hindu & $12(60 \%)$ & $3.41 \pm 0.51$ & 0.96 & \\
\hline \multirow[t]{2}{*}{ Occupation } & $\begin{array}{c}\text { Muslim } \\
\text { Christian } \\
\text { Others } \\
\text { Housewife }\end{array}$ & $\begin{array}{c}0(0 \%) \\
1(5 \%) \\
7(35 \%) \\
15(75 \%)\end{array}$ & $\begin{array}{l}0.00 \pm 0.00 \\
3.00 \pm 0.00 \\
3.14 \pm 0.37 \\
3.26 \pm 0.45\end{array}$ & 1.19 & $\begin{array}{c}0.32 \\
N S, p>0.05\end{array}$ \\
\hline & $\begin{array}{l}\text { Daily Wages } \\
\text { Employees }\end{array}$ & $\begin{array}{c}1(5 \%) \\
4(20 \%)\end{array}$ & $\begin{array}{l}4.00 \pm 0.00 \\
3.25 \pm 0.50\end{array}$ & & \\
\hline
\end{tabular}


Table No.4 shows the mean, standard deviation and range of behavioral responses of primigravida mothers in the experimental group before breathing exercises. The mean score for behavioral responses is 8.70 and standard deviation is 0.65 and the ranges for behavioral responses are between 8 and 10 .

Table No.5 reveals the mean, standard deviation and range of behavioral responses of primigravida mothers in the control group. The mean score for behavioral responses is 8.85 and standard deviation is 0.58 and the range for behavioral responses was between 8 and 10 .

\section{Section D: Assess the effectiveness of breathing exercise on labour pain among primigravid mothers during first stage of labour.}

The above table illustrates the effect of breathing exercises on pain during the first stage of labour among primigravida mothers in the experimental group. The assessment is done before and after breathing exercises. The mean, standard deviation and range are compared, and student's paired 't' test was applied at 5\% level of significance. The mean score for pain before breathing exercises and after breathing is 8.85 and is 3.30. The standard deviation for pain before and after breathing exercises is 0.67 and 0.47 . The range before and after breathing exercises is between $8-10$ and $3-4$.

Statistically there is significant decrease in pain in the experimental group after breathing exercises during the first stage of labour. The tabulated 'for $19 \mathrm{df}$ is 2. 09 and calculated' value for pain is 41.03 . The calculated ' $t$ ' value was higher than the tabulated value at 5\% level of significance which is statistically acceptable level of significance $(p=0.000<0.05)$.

Assess the effectiveness of breathing exercise on behavioral responses among primigravid mothers during first stage of labour

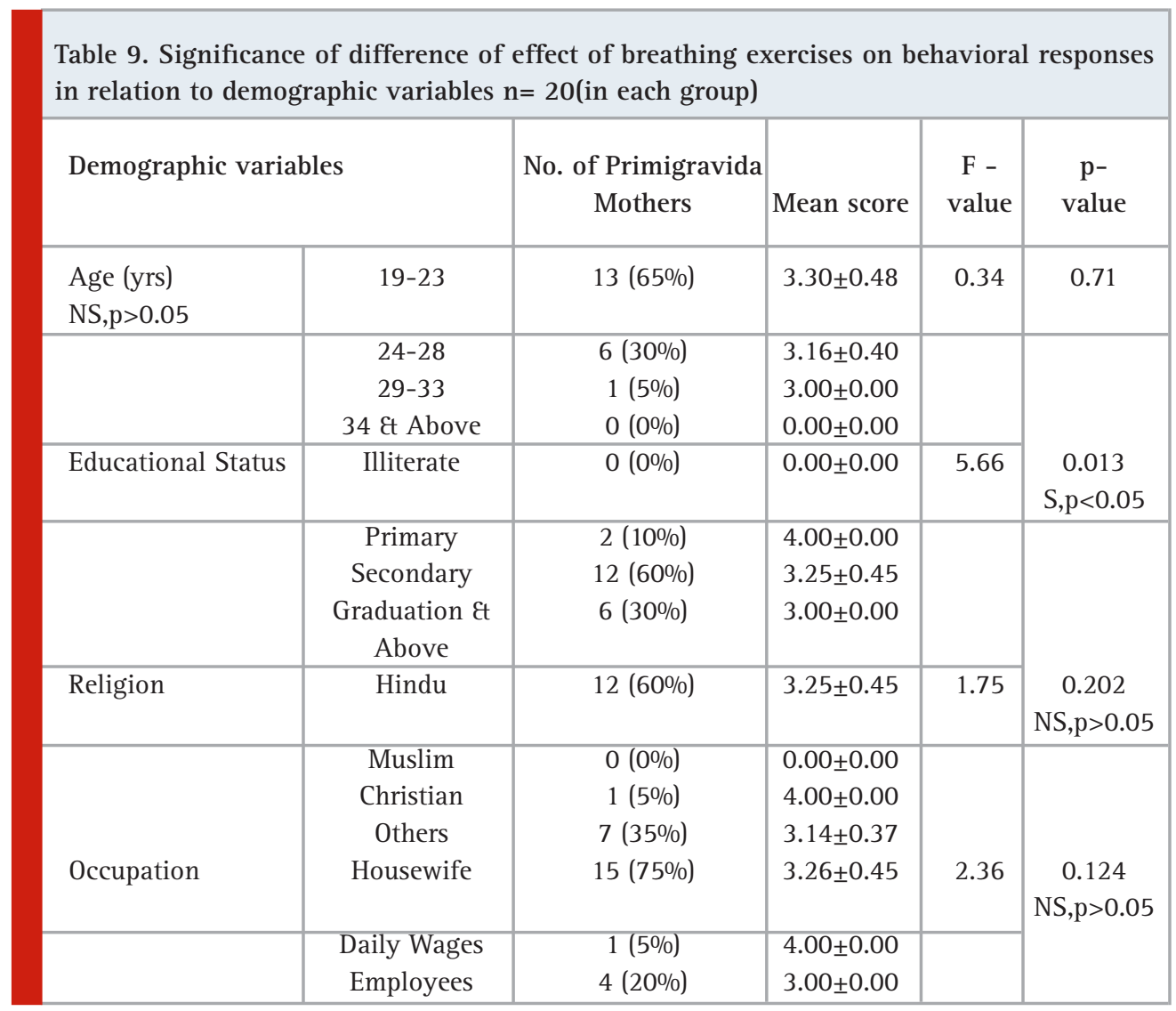

The above table illustrates the effect of breathing exercises on behavioral responses during the first stage of labour among primigravida mothers in the experimental group. The assessment is done before and after breathing exercises. Mean score for behavioral response before and after breathing exercises is 8.70 and 3.25. Standard deviation before and after breathing exercises is 0.65 and 0.44 . The range before and after breathing exercises is between 8 - 10 and between 3 - 4. Mean difference for pain is between $5.55 \pm 0.60$ and for behavioral responses it is between $5.45 \pm 0.68$.
Statistically there is significant decrease in behavioral responses in the experimental group after breathing exercises during the first stage of labour. The tabulated'for $19 \mathrm{df}$ is 2.09 and for Behavioral responses, calculated ' $t$ ' value35.51 is higher than the tabulated ' $t$ ' value at $5 \%$ level of significance which is statistically acceptable level of significance $(p=0.000<0.05)$. Hence research hypothesis H2is accepted.

Section E (A): Associate the effect of breathing exercise on pain during the labour pain among primigravid 
mothers in the experimental group with the selected demographic variables

This section deals with the association of the effect of breathing exercises on pain during first stage of labour among primigravida mothers in the experimental group with selected demographic variables.

The above table depicts the significance of difference of effect of breathing exercises on pain in relation to age. Number of primigravida mothers between the age group of $19-23$ years is 13 and means score is $3.23 \pm 0.4 .3$ and the majority are belonging to this group. Number of Parturient Mother between the age group of $24-28$ years is 6 and the mean score is $3.50 \pm 0.54$. Between the age group of 29 - 33years is only one and the mean score is $3.00 \pm 0.00$ and there as nobody between the age group of 34 years and above. Calculated ' $\mathrm{f}$ ' value is 0.87 and 'p' value is 0.43 which is more than the accepted level of significance i.e ' $p$ ' $=0.05$. Hence it is interpreted that effect of breathing exercises on pain in relation to the age is not significant in this study.

Table shows the significance of difference of effect of breathing exercises in relation to the educational status. There is no one in the illiterate and 2 are having primary education. The mean score is $3.50 \pm 0.70$. Majority is having secondary education i.e 12 and the mean score is $3.33 \pm 0.49$. Number of primigravida mothers having Graduation and above education is 6 and the mean score is $3.16 \pm 0.40$. The calculated ' $\mathrm{f}$ ' value is 0.42 and 'p' value is 0.66 which is more than the accepted level of significance i.e ' $p$ ' $=0.05$. Hence it is interpreted that effect of breathing exercises on pain in relation to the age is not significant in this study.

This table reveals the significance of difference of effect of breathing exercises on pain in relation to religion. Majority of primigravida Mothers i.e 12 are belong to the Hindu religion and the mean score is $3.41 \pm 0.5$. There was no one belong to Muslim religion and only 1 belong to the Christian religion and the mean score is $3.00 \pm$ 0.00.Primigravida mothers belong to the other religion is 7 and the mean score is $3.14 \pm 0.37$. Calculated ' $\mathrm{f}$ ' value is 0.96 and 'p' value is 0.40 which is more than the accepted level of significance i.e ' $p$ '= 0.05 . So it can interpret that effect of breathing exercises in relation to religion is not significant.

The above table depicts the significance of difference in effect of breathing exercises on pain in relation to occupation. Majority of primigravida mothers i.e. 75\% are housewife and the mean score is $3.26 \pm 0.45$. Daily wages are 5\% and mean score is $4.00 \pm 0.00$. Employees are $20 \%$ and the mean score is $3.25 \pm 0.50$. The calculated ' $\mathrm{f}$ ' value is 1.19 and $\mathrm{p}$ ' value is 0.32 which is more than the accepted level of significance i.e ' $p$ ' value $=0.05$.So it can interpret that effect of breathing exercises on pain in relation to occupation is not significant.

Section E-(B): Associate the effect of breathing exercise on behavioral responses during labour pain among primigravid mothers in the experimental group with selected demographic variables.

The above table depicts the significance of difference of effect of breathing exercises on behavioral responses in relation to age Number of primigravida mothers in the age group between $19-23$ are 13 and he mean score is $3.30 \pm 0.48$. Between the ages group of $24-28$ is 6 and the mean score is $3.16 \pm 0.48$. Between the ages group of $29-33$ is only one and the mean score is $3.00 \pm$ 0.00 . There is no one between the age group of 34 and above. The calculated ' $\mathrm{f}$ ' value is 0.34 and ' $p$ ' value is 0.71 which is more than the accepted level of significance i.e 'p' value $=0.05$. So it so it can interpret that effect of breathing exercises on behavioral responses in relation to age is not significant.

Above table shows the Significance of difference of effect of breathing exercises on behavioral responses in relation to educational status. In the illiterate group there is no body, in primary education there is 2 and the mean score is $4.00 \pm 0.00$. In the secondary education group there is 12 and the mean score is $3.25 \pm 0.45$. Graduation and above there is 6 and the mean score is 3. $00 \pm 0.00$. Calculated ' $f$ ' value is 5.66 and 'p' value is 0.013 which is less than the accepted level of significance i.e 'p' value $=0.05$. So it can interpret that effect of breathing exercises on behavioral responses in relation to education has a positive association in this study. The above table reveals the Significance of difference of effect of breathing exercises on behavioral responses in relation to religion. Majority of the primigravida ie 12 are belong to Hindu religion and the mean score is 3.25 \pm 0.45 . There is no one belong to the Muslim religion, only 1 belongs to the Christian religion and the mean score is $4.00 \pm 0.00$. Number of primigravida belong to other religion is 7 and the mean score is $3.14 \pm 0.37$. Calculated ' $\mathrm{f}$ ' value is 1.75 and the ' $\mathrm{p}$ ' value is 0.202 which is more than accepted level of significance i.e ' $p$ ' value $=0.05$.So it can interpret that effect of breathing exercises on behavioral responses in relation to religion is not significant.

The above table illustrate the Significance of difference of effect of breathing exercises on behavioral responses in relation to occupation. Majority of the primigravida mothers i.e. 75\% are housewives, the mean score is 3.26 \pm 0.45 . Daily wages is $5 \%$, mean score is $4.00 \pm 0.00$ and employees are 20\% and the mean score is $3.00 \pm 0.00$. Calculated ' $\mathrm{f}$ ' value is 2.36 and the ' $p$ ' value is 0.124 which is more than accepted level of significance i.e ' $p$ ' = 0.05. So it can interpret that effect of breathing exercises on behavioral responses in relation to occupation is not significant in this study.

Nursing Implications: The findings of this study have implications for nursing practice, nursing education, nursing administration and nursing research.

Nursing Services: For centuries, human touch has been shown to be emotionally and physically healing. Particular massage techniques may either stimulate or 
calm the body's muscles and tissues to create a desired effect. When massages soft tissue, electrical signals are transmitted both to the local area and throughout the body. These signals, in combination with the healing properties of touch, help heal damaged muscle, stimulate circulation, clear waste products via the lymphatic system, boost the activity of the immune system, reduce pain and tension, and induce a calming effect. Massage may also enhance well being by stimulating the release of endorphins (natural painkillers and mood elevators) and reducing levels of certain stress hormones.

The most important role of the nurse is to provide individual, family and community oriented service with adequate attention to vulnerable group of the community. The nursing services should be based on felt needs of the people. The nurse should be responsible for preventive, promotive, curative and rehabilitative aspects of care.. The most important is the preventive aspect of the care which is best achieved through the health education. The present study will help the nurses for coordinating health care services to health care professionals.

Nursing Practice: When professional liability is recognized, it defines the parameters of the profession and the standards of professional conduct. Nurses should therefore enhance their professional knowledge. The nurse can incorporate throughout labour is the promotion of relaxation through the use breathing exercises. Pace breathing exercises have been shown to the factors in promoting the labour progress, decreasing pain perception, increasing the women's ability to cope with labour. The midwifery nurse should consider that every primigravida mothers are the consumer of nursing and health care. The nurse can provide knowledge about pace breathing exercises to the mothers and the nurse can utilize to create awareness among the other health care personnel regarding the same.

Nursing Education: Nursing education helps the students with adequate knowledge, skill and attitude to fulfill their duties and responsibilities in the nursing field. The awareness of use of pace breathing exercises during the first stage of labour should be emphasized in the curriculum. The knowledge of health professional can be improved by the conducting in service education in the curriculum.

Nursing Administration: Findings of the study can be used by the Nursing Administrator in creating policies and plan for providing education to the nursing staff regarding the use of pace breathing exercises during the first stage of labour.. In-service education programme to be initiated for nurses to update knowledge regarding the use of non pharmacological approaches to the management of first stage of labour. More information in the form of booklets, pamphlets can be given to the nurses.

Nursing Research: Nursing research is an essential aspect of nursing as it uplifts the profession, develop new nursing norms and enhance the body of nursing knowledge. Nursing research improves the image and perception of nursing in society which is urgently required for the future of nursing. It also motivate for evidence based practice. There is a need for extended and intensive nursing research in the areas of one of the non pharmacological approach i.e. effect of pace breathing exercises during the first stage of labour in primigravida women. It is based on the principles of nursing interventions. The findings of the study have added the knowledge in the nursing profession. Other researchers may utilize the suggestions and recommendations for conducting further study. The tool and technique used has added to the body of knowledge and can be used for further references.

Recommendations: Keeping in view the findings of the study, the following recommendations are made

1. A same study can be conducted on large samples so that it can be generalized.

2. A similar study on selected non pharmacological approach towards the management of first stage of labour can be conducted.

3. A comparative study to find out similarities or differences between rural and urban mothers regarding the use of effect of pace breathing exercises on pain and behavioral responses during the first stage of labour.

4. A study to assess the knowledge of staff nurses regarding the effect of pace breathing exercises on pain and behavioral responses during the first stage of labour among primigravida.

5. A comparative study can be conducted by using back massage and pace breathing exercises.

6. A comparative study can be conducted on pace breathing exercises by the health care personnel and the life partner.

\section{DISCUSSION}

Breathing exercise is a natural way to relieve labour pain.. Mothers who have used breathing exercise during child birth have been incredibly satisfied with this natural method. So it is valuable to offer complementary pain relief methods to women in childbirth. Most childbirth education classes and most books on childbirth present relaxation techniques, along with a variety of rhythmic breathing patterns intended to complement and promote relaxation or to provide distraction from labor pain. They are also used to enhance a woman's sense of control.

A similar study was conducted by Jayabharathi.B to assess the effectiveness of relative nursing interventions (such as breathing exercise, massage and positions) on pain during labour among primigravida mothers. In this study the post-assessment level of labour pain perception of primi mothers showed a mean value of 3.33 with SD of 1.86 in experimental group and mean value of 5.69 with SD of 2.59 in control group. The mean value (3.33) of experimental group was comparatively lower than the mean value (5.69) of control group. Therefore the study 
concluded thatselected nursing interventions (such as breathing exercise, massage and positions) to the primi mothers were effective in reducing their labour pain perception in experimental group.

This study was similar to another findings conducted in Coimbatore indicating there was a significance difference between the mean pain scores of experimental group (4.28) was lower than the mean pain scores of control group (6.22) which shows that that the slow paced breathing initiated by the investigator was effective in reduction of pain during the first stage of labour. Another study similar to this study is a study conducted in the city of Goiânia, in the state of Goiás (G0), Brazil, using individualized assistance with guidance and encouragement of breathing exercises and muscle relaxation techniques during labor, it was found that in the active phase of labor there was a predominance of pain; with the increase in pain tolerance during labor, encouragement, force, and physical and psychoemotional well-being occurred in that period. 17 Another study using methods of progressive muscle relaxation showed significant reduction in the level of pain in parturient women subjected to this technique.

A survey of women in the United States who gave birth in 2005 found that 49 percent of the respondents used breathing techniques, and of those, 77 percent rated them as "very" or "somewhat" helpful, while 22 percent rated them as "not very helpful" or "not helpful at all" 17 This finding may reflect differences in the quality of the teaching received by the women, or indicate that breathing techniques are not helpful for everyone. A survey of British women found that 88 percent of women who reported using relaxation techniques found them to be "good" or "very good". Findings of the study clearly indicate that breathing exercise is an effective complementary means for inducing a relief from labour pain $(p<0.01$ as per t-test). Hence the null hypothesis is rejected at 0.05 level of significance. So it is concluded breathing exercise is effective in decreasing intensity of labour pain. So it can be effective nursing management for women in labour.

\section{CONCLUSION}

As mothers pass into labour, the frame briefly is going right into a panic reaction because of the pressure of the moment. This induces panic respiration that's shallow and rapid. It has been discovered that respiration and rest strategies significantly lessen the depth of labour pains and girls to have greater manipulate of their bodies and assist them deal with contractions better. There changed into a enormous depletion in labour ache on the primary degree of labour concerning primigravida moms after training the patterned respiratory approach, thus it has confirmed to be an powerful approach for lowering labour ache. Therefore, this intervention should be advocated as health facility coverage and applied as recurring take care of all of the primigravida moms in first degree of labour for lowering labour ache

\section{Source of Funding: Self-Funding}

Ethical Clearance: Prior permission was obtained from the Institutional Ethical Committee (Datta Meghe Institute of Medical Sciences (Deemed to be University), Wardha. Ref. No. DMIMS (DU)/IEC/2017-18/6777. Informed written consent was taken from each participant under the study. An objectives of the study was maintained with honesty, privacy confidentiality and anonymity.

\section{Conflict of Interest: Nil}

\section{REFRENCES}

Asnat Walfi. (2007) A rise in pain threshold during labour, A prospective clinical trial: Journal of international association for the study of pain;132(48):104-108.

Basil R. (2001) The effectiveness of back massage and breathing exercises on pain relief in primi mothers retrieved from Breathing techniques. American Journal Of Nursing; 26(7): 4-8. Accessed Jul 29, 2013.

Dealing with labour pain during child birth.Available from URL: http://www.child birth. / first stage of labour /labour.html. Accessed November 11, 2013.

Field T, Hernandez-ReifM,Taylor S, Quintino0,BurmanI. (1997) Labour pain is reduced by massage therapy. obstetrics and gynaecology journal, Dec;18(4):286-91. Grace Addison.( 2013) Relieve labour pain by exercising whilepregnant. Available from: URL:http://www.can_ really/relieve/labour/pain.12423324.Accessed August 14.

Jayasudha, (2013) Effectiveness of antenatal exercises on outcome of labour and behavioral responses of primigravid women in first stage of labour. Available from: URL:http;//www.muhs.in/onlinedu/34895.doc. html. Accessed September 23.

Karkada E.C., (2013) Effectiveness of childbirth preparation class in terms of behavioural responses during first stage of Labour and outcome of labour among primi gravid mother Availablefrom:URL:http:// www.muhs.in/onlinedu/86974.doc.html.Accessed November 12.

Kavitha V. (2011) Lamaze method on primigravida women during first stage of labour.Asian journal of nursing education. Jan-March; 1(1):25-7.

Kuti.O, Faponle. A. (2013) Physiology of pain in labour. Journal of Obstetrics and Gynecology 2006 Jun 26; 55(5):332-334.Accessed Jun 12.

Labour introduction mediindia. Availablefrom: URL:http://www.mediindia.net/ patient info/labour.html Accessed Jun 13, 2013.

Lowdermilk, perrycashion. (2010) Maternity Nursing.8th ed. California: Elsevier publishers; p. 288-91.

Nancy KL. (1996) The pain and discomfort of labour and birth: pain management. Jognn,;25(1):82-92. 
Saldanha H.( 2013) Effectiveness of breathing exercises on duration, outcome of labour, and behaviour responses of gravid women during the first state of labour in a selected hospital at Mangalore.Available from: URL:http://www.rguhs. ac.in/cdc/onlinecdc/ uploads / 05-N867-12367.doc.html. Accessed Jul 10. Simar.P.Rojen. Pain reducing therapy during labour. The Nursing Journal of India, June 2010, march 1;77:679683.

Sinhgad. (2011) Breathing exercise on labour pain.
e-Journal of Nursing. dec 1(2):673-80.

Sylvia T. Brown, Carol Douglas, Lee Ann Plaster Flood. Breathing exercise in labour pain Journal of Prenatal Education2001. Available from:URL:http://www. breathing/labor/mothers.com.html. Accessed August 3, 2013.

Yildrim.G, Sabin NH. (2004) The effects of breathing and skin stimulation techniques on labour pain perception of Turkish women. Journal of pain management[serial online];9(4):183-87. 